\title{
Reflexiones historiográficas desde la historia cultural
}

\section{Historiographical reflections from cultural history}

\author{
Stefany Liddiard Cárdenas* \\ Francisco Alberto Pérez Piñón***
}

\begin{abstract}
* Profesora de la Universidad de Ciencias del Comportamiento (México). Es maestra en Psicología Social y de las Organizaciones. Entre sus publicaciones recientes están: "Herramientas de la sociología de la educación aplicadas en la comunidad Mormona LeBaron en Chihuahua," en la revista sociológica Núm. 92 (32) (2017); capitulo de libro: "Representaciones sociales: colonia LeBaron Chihuahua" (2017). Es socia activa de Red de Investigadores Educativos Chihuahua. Sus temas de interés son la historia e historiografia de la educación. Correo electrónico stefanyliddiard@gmail.com
\end{abstract}

(D) https://orcid.org/0000-0002-3234-4372

**Profesor investigador de la Universidad Autónoma de Chihuahua (México). Es doctor en Ciencias Pedagógicas (Cuba). Entre sus publicaciones recientes están: "Apuntes para una historia posmodernista" en Espacio abierto vol. 25, n.4 (2016); capitulo de libro "La hacienda de coyotillos, un acercamiento a los contenidos educativos" en Acercamientos a la historia de la educación, diálogos actores y fuentes en la construcción del conocimiento histórico (2017). Desarrolla la línea de investigación Historia e Historiografia de la Educación. Cuenta con reconocimientos Prodep y del Sistema Nacional de Investigadores Nivel 1. Es miembro de la Sociedad Mexicana de Historia de la Educación, del Consejo Mexicano de Investigación Educativa y de la Red de Investigadores Educativos Chihuahua. Correo electrónico aperezp@uach.mx

(D) https://orcid.org/0000-0003-4316-6484

\section{Historial editorial}

Recibido: 15-mayo-2018

Primera revisión: 20-mayo-2018

Segunda revisión: 03-agosto-2018

Aceptado: 08-septiembre-2018

Publicado: 31-octubre-2018 


\section{Reflexiones historiográficas desde la historia cultural}

\section{Resumen}

En este texto se muestra como referente la investigación doctoral titulada El sentido de identidad de la comunidad de los mormones fundamentalistas de Chihuahua, con la cual se exponen una serie de reflexiones elaboradas desde una marcada línea de pensamiento de la historia cultural, la cual ejerce influencia al analizar e interpretar los procesos subjetivos de una agrupación de mormones fundamentalistas; en los que el simbolismo, la vida cotidiana y el imaginario social se rescatan como elementos que conforman el sentido de identidad de esta comunidad. Se ofrece un recorrido en las formas de hacer historia, enfocándose en las características propias de la historia cultural y sin pretender generalidades, se presentan ciertos distintivos o rasgos mediados por aspectos teóricos y metodológicos que fueron aplicados a la investigación, el centro de estas explicaciones.

Palabras clave: Historia e historiografía, historia cultural, identidad. 


\title{
Historiographical reflections from cultural history
}

\begin{abstract}
This paper is concerned with presenting results from a doctoral dissertation about a group of Fundamentalist Mormons and whose purpose is to analyze and interpret, from a distinctive cultural historical line of research, the symbolism, daily life and the social imaginary, as elements that make up the sense of identity of this community. The paper describes cultural historical research, some of its distinctive features, and presents, with no pretension to generalize, theoretical and methodological aspects that sustain the results of this research.
\end{abstract}

Keywords: History and historiography, cultural history, identity. 


\section{Introdución}

"Y sin embargo se mueve" frase que ha ganado una serie de discusiones en cuanto a su veracidad y si fue o no Galileo Galilei el autor de este pensamiento, disputa en la que no me detendré; solamente recurro a ella como una alegoría a la esencia en la investigación social, ya que el ser humano como parte de la naturaleza recibe sus propiedades de forma transitiva, lo que hace pensar que las teorías y metodologías en la investigación son de igual forma, activas e inestables. Es por ello que tanto los historiadores como sus líneas o escuelas formadoras han manifestado cambios significativos originados en una dinámica social que con sus movimientos exigen transformaciones en todos sus niveles.

Se señala lo anterior ya que, en el caso de los trabajos históricos, la gran diversidad de interrogantes que los originan han redireccionado hacia una visión plagada con una multiplicidad de abordajes teóricometodológicos o bien, numerosas formas de hacer historia. Precisamente estas necesidades sociales deben ser la fuerza que impulse los cambios o modificaciones en la disciplina historiográfica, más allá de surgir por novedad o la simple utilización de los métodos en boga.

Si bien la transformación de las formas historiográficas contiene un sinnúmero de fases, elementos, conceptos, críticas, etc., en este texto se detallan ciertos elementos de la historia cultural como la tipología histórica con la que se argumenta el quehacer investigativo, mismo que

144 sirve de sustento al testimoniar su aplicación en una comunidad de mormones fundamentalistas en Chihuahua.

Debido a lo anterior, es necesario esbozar el recorrido de estas formas de hacer historia, destacando el momento que se consideró a la historia 
cultural como una de ellas y cuáles son los elementos clave que le caracterizan como tal.

Pero antes de continuar me permito reflexionar acerca de un par de cuestionamientos. El primero de ellos recae en el hecho que, a pesar de la legitimación propia de la historia cultural, los trabajos en esta línea aún son pensados y asignados a los antropólogos o expertos en temas culturales, cuestionando al historiador cuando trabaja en esta área. El segundo y no menos importante, surge del arraigo de algunas personas al considerar que la historia solo puede emerger de los documentos históricos, los cuales además de permanecer recluidos o enclaustrados en un archivo por varios años, han de cubrir ciertos requisitos para figurar como documentos valiosos y fidedignos para ser recuperados y analizados. Cuestionando finalmente, lo que se responderá a lo largo de este texto, lo que acontece día a día puede considerarse o no como parte de una historia constituyente, conformada con los procesos sociales emanados de la cotidianeidad, y si es posible a través de esta, conservar la memoria cultural e histórica de una comunidad.

Ahora bien, para iniciar a dibujar lo que es la historia cultural se recupera lo expuesto por Juan Manuel Santana, en lo concerniente a la historia admitida como ciencia moderna, la cual ha evolucionado en lo teórico y por supuesto en lo epistemológico. En su obra del 2005, Santana organizó el transcurso de los paradigmas historiográficos en cuatro fases o momentos: el positivismo, la escuela de los Annales, el materialismo histórico y la posmodernidad.

Santana utilizó el término historia cultural al detallar el desarrollo de la escuela francesa de los Annales; la cual dio paso a una historia distinta a la positivista, al considerar elementos y temas diferentes a la política, milicia, discursos del Estado o aquellos centrados en los hombres pertenecientes a la gran élite. En este primer cambio fue posible dar un 
salto a la interdisciplinariedad, principalmente la historia con la sociología, comenzando a concebir la causalidad histórica estructural, desde "las estructuras básicas, y más profundas, del proceso histórico" (Santana, 2005, p. 52). Este cambio para Santana, citando a Le Goff, estuvo también en el "reemplazo de la historia-relato por la historiaproblema, prestar más atención al presente de la historia” (p. 53).

A partir de este momento se dio paso a la elaboración de estudios regionales más cercanos a los acontecimientos, además de considerar la vida cotidiana, elaborar un trabajo artesanal, tener acceso a casi toda la documentación disponible y por supuesto el "seguir la evolución de un grupo social en una larga duración, analizando distintos niveles estructurales" (Santana, 2005, p. 55).

Continuando en esta fase de la historia, un momento relevante fue en mayo de 1968 cuando Fernand Braudel abandonó la dirección de la revista de los Annales y dicha labor se hizo colegiada; a partir de ese momento destacó la cantidad de artículos de historia cultural publicados, resaltando que la "investigación se abre a nuevos campos: antropología, psicología social, lingüística...el discurso histórico sufre una etnologización" (p. 6o). Santana distingue a esa generación en la revista como poseedora de tres distintivos: el primero fue el interés hacia la realidad cultural con el dominio de la historia de las mentalidades, el segundo la fragmentación de los objetos de estudio y finalmente el tercero con el abandono de la visión positivista "dejando su lugar a la historia de lo cotidiano. A la par de todo ello, la antropología ha reemplazado a la sociología en el interés de los historiadores" (2005, p. 68). Fue precisamente el otorgamiento de la preponderancia histórica de lo cultural junto a las aportaciones de sus representantes lo que hizo valioso este momento y que actualmente renueva la actividad historiográfica. 
A partir de la década de los ochentas, este mismo autor, indica que las historias tomaron su camino hacia lo mental, por lo que "convergen en la historia del imaginario, es decir, que las representaciones imaginadas (imágenes, símbolos y realidades inventadas) desplazan el interés anterior por otras funciones mentales” (p. 77). Así mismo:

Debemos entender, por lo tanto, la historia de las mentalidades como el estudio de las meditaciones y de relación dialéctica entre las condiciones de vida de las personas y la manera en que la cuentan y aun en que la viven (p.78).

La utilidad de especificar este salto teórico se debe a las formas de concebir la historia, la cual se enfoca en las cotidianidades de la sociedad, en investigaciones sobre las formas de convivencia y los imaginarios que producen, los cuales permiten la construcción y reproducción de la cultura de los grupos.

\section{Apuntes de la historia cultural}

Después de presentar el breve recuento de los cambios en la historiografía y el quehacer del quien la escribe; me permito mostrar una síntesis de algunos planteamientos elaborados por Peter Burke, quien centra su trabajo en la historia cultural y resalta por ser uno de los principales autores en esta línea.

Semejante en la organización por etapas elaborada por Santana, Burke (2004) indicó que la historia cultural se puede dividir en cuatro fases: la primera llamada clásica, la segunda reconocida como la historia social del arte, posteriormente la nombrada historia cultural popular y finalmente la conocida como nueva historia cultural. 
La primera de estas fases se caracteriza por que los escritores de esa época se centraban en la historia de los clásicos en arte o la literatura. Jacob Burckhardt, Johan Huizinga y G.M. Young son tres de los historiadores que recupera Burke como los más representativos; fue precisamente en uno de los ensayos publicados por Huizinga en I929, donde indicó que:

El principal objetivo del historiador consiste en retratar patrones de cultura, es decir, describir los pensamientos y los sentimientos característicos de una época y sus expresiones o encarnaciones en obras literarias y artísticas. El historiador, sugería, descubre estos patrones culturales estudiando $<$ temas $>$, $<$ símbolos $>$, <sentimientos $>$ y <formas $>$ (Burke, 2004, p. 22).

La segunda fase se caracterizó principalmente por las contribuciones de estudiosos alemanes quienes "trabajaban al margen de los departamentos de historia" (2004, p. 23). Trabajos que partieron de un análisis cultural del cambio económico elaborado por Max Weber, quien destacó los valores de los protestantes considerando una sociología comprensiva; pasando por el "desarrollo gradual del autocontrol o el control de las emociones" (p. 24) a través de la historia de los modales en la mesa de la Europa occidental por Norbert Elias; hasta el estudio de "los esquemas o formulas culturales o perceptivas" (p. 25) de Aby Walburg. Como ellos, otros más fueron el preámbulo de la interpretación de las culturas, ya que comenzaron a escribir acerca de esquemas, símbolos y las representaciones figuradas desde la iconología.

Décadas posteriores, con la idea de rescatar la historia cultural popular de los bailes, ritos, oficios, cuentos y mitos, la cual se consideraba asunto de antropólogos o de los interesados por el folclore, existió una 
transición que según Burke (2004) culminó hasta la década de los sesentas cuando esta historia competería a historiadores académicos.

Citando a Burckhardt "la historia cultural posee un grado primario de certeza, pues consta en su mayor parte de material transmitido de modo no intencionado, desinteresado o incluso involuntario por las fuentes o monumentos" (Burke, 2004, p. 36). En este planteamiento se deduce que el acercamiento a esta historia será el resultado de distintas interpretaciones.

En palabras de Burke (2004) la nueva historia cultural como la cuarta fase, mostró un nuevo historicismo a nivel internacional, tomó fuerza en diferentes áreas dependiendo el país. En Estados Unidos los historiadores se centraron en la literatura; en Francia la historia de las mentalidades y el imaginario social se abrieron camino rápidamente, siendo Roger Chartier uno de los representantes más significativos de la misma; la tradición de la vida cotidiana tuvo mayor presencia en Holanda y Alemania, recuperando autores como a Burckhardt y Huizinga. Siendo en Gran Bretaña donde los estudios culturales también cobraron mayor impulso.

Especialmente en este texto se le otorga mayor peso a Clifford Geertz (1994) quien con la interpretación de la cultura otorgó mayor importancia a los símbolos y significados, además, con el uso de la etnografía comprendió el mundo simbólico y al realizar interpretaciones le fue posible encontrar el significado que le otorgan las comunidades a sus formas culturales.

Un seguidor de Geertz fue Robert Darnton quien en una serie de ensayos "definió la tarea del historiador cultural como <la captura de la alteridad $>$ y, siguiendo en particular a Geertz, sugirió que $<$ uno puede 
leer un ritual o una ciudad lo mismo que puede leer un cuento popular o un texto filosófico>" Burke (2004, p. 55).

En conclusión, se identifica precisamente que con el giro cultural se admitió que la historia colaborara con otras disciplinas, lo que posibilitó que no permaneciera aislada como lo había sido la historia clásica. Fue un movimiento que, sin atamientos, empujes ni deformaciones, permitió dentro de la figura histórica el préstamo teórico-metodológico en forma de diálogo.

Precisamente se extrae como fundamento relevante que la historia cultural desde sus orígenes en la mencionada historia de los Annales, estuvo empatada con una historia preocupada por comprender algo más que los hechos, guerras, encuentros o desencuentros; hasta hoy ha sido una disciplina interesada en el acontecer al interior de los grupos, una mezcla artística emanada al trabajar con agrupaciones y sus componentes, sean tangibles o no.

\section{La aplicación en la comunidad fundamentalista}

Se inicia este apartado a manera de contexto y para situar a los lectores, explicando quienes son los mormones fundamentalistas a los que se recurre en varias ocasiones en este texto. Si bien existen varias órdenes inscritas en este término, en este caso se consideraron aquellos miembros que continúan con los preceptos de la Iglesia del

150 Primogénito de la Plenitud de los Tiempos, una agrupación que congrega desde I955 a varios cientos de personas que radican principalmente al noroeste del estado de Chihuahua. Se consideran mormones porque sus preceptos son derivados de la Iglesia de Jesucristo de los Santos de los Últimos Días originada desde i830 en 
Estados Unidos de Norteamérica y conocida comúnmente como mormona. También es necesario esclarecer que entre ambas existen diferencias sustanciales, la primera de estas iglesias además de haber iniciado una nueva filial, mantiene algunas ordenanzas que fueron primigenias de la segunda pero ya no lo son, razón por lo cual se consideran disidentes. Se les nombra como fundamentalistas ya que el término indica la corriente, en este caso religiosa, que mantiene una traducción literal, sin modificación alguna de los textos y la aplicación de prácticas o costumbres inmutables.

Ahora bien, la principal preocupación investigativa en la comunidad mormona fundamentalista en Chihuahua fue todo este mundo simbólico, descrito desde el inicio. Este espacio a interpretar se concibe como un cúmulo de subjetividades delimitado por los umbrales culturales e identitarios, convirtiéndose en el interés principal para el acercamiento a esta agrupación. Fue así como se articuló a la historia cultural como la disciplina que permitió estudiar los ejes, conceptos y directrices en esta investigación, los cuales están enfocados en la reconstrucción del recorrido histórico y por supuesto los procesos educativos correspondientes.

Se reconoce también el interés en rescatar aquello que no ha sido contado por propios, la pretensión de contar una historia que deje vestigio de una comunidad que, al ser parte de un sistema, está interrelacionada con otras sociedades en varios de sus niveles. Estas narrativas junto a la interpretación elaborada por el investigador ofrecen un posicionamiento para identificar las relaciones o conjeturas obtenidas, las cuales están organizadas en distintas áreas, dimensiones y conceptos.

Una de las aportaciones principales fue responder de cierta forma el cuestionamiento de Burke al enunciar que "el gran problema estriba en 
analizar la relación entre la comunidad y el mundo exterior" (2004, pp. 64-65). Pues si bien la heterogeneidad de los grupos hizo de esta tarea algo complejo; se identificaron varias y no solo una relación de esta comunidad con otras, entre las que resalta el proceso de aculturación como un fenómeno que ha ido modificando y trastocando los procesos culturales y por ende su identidad. Se percibió una sociedad dominante que impone estilos de vida y convivencia sobre dicha comunidad minoritaria, que se muestra cohesionada aun por ciertos elementos arraigados, principalmente en lo religioso, pero con una tendencia a desaparecer en el trascurso del tiempo.

El incursionar y delimitar estos espacios no fue fortuito, al realizar el trabajo etnográfico se identificaron los principales ejes en los que se centraría el trabajo; junto a la relevancia otorgada a los procesos informales de la educación, se unieron las implicaciones de este tipo de educación para la conformación, permanencia y cambio de toda una comunidad; por ello fue que la familia, iglesia, escuela, comunidad y otros agentes más, se retomaron en esta reconstrucción identitaria. Hay que recordar que desde esta perspectiva histórica no solo se estuvo interesado en los acontecimientos, también se preocupó por el sufrimiento, el gozo, y aquellas situaciones y emociones que claramente tienen repercusiones en los individuos y grupos, quedando grabadas en su memoria colectiva, particulares a esta comunidad.

El considerar elementos como la cordialidad, la solidaridad, los valores familiares y comunales, así como adentrarse en ciertas formas de vida y convivencia, se justifica por considerarles actos interrelacionados, maquilados por propios, motivados en la coexistencia, dirigidos a conseguir elementos de praxis y lograr mayor conocimiento personal y social. Por un momento parecieran ser que los renglones ya leídos están plagados de información destinada a expertos instalados en las ciencias 
de la psique, por mezclar procesos sociales y su influencia en lo individual y viceversa.

En realidad, se pretende mostrar la cercanía existente entre las consideraciones mencionadas y el nexo con el interés anclado en la historia cultural. Esto quedará esclarecido poco a poco. Primero se indica que conforme a la pretensión general investigativa de interpretar la vida cultural correspondiente a una microsociedad fue necesario incursionar también en la cotidianidad, es decir, indagar sobre estos aspectos subjetivos que constituyen la convivencia entre los miembros de esta comunidad. Para todo esto fue preciso convivir y conocer las formas de vida de una comunidad rural compuesta por personas descendentes de norteamericanos, que se comunican en otro idioma, físicamente diferentes a la población mexicana, que tienen costumbres y tradiciones que no encajan del todo con aquellos que les rodean, personas que resaltan por ser hombres y mujeres dedicados al trabajo y a conformar grandes familias en las que postergan los valores, formas de vida y de existencia.

Lo que acontece en las calles, hogares, durante las comidas familiares o comunales, en las reuniones o celebraciones, fueron los eventos, por mencionar algunos, en los que se logró identificar ciertos acomodos de estructuras mentales y sociales (sin mostrar un posicionamiento desde la sociología o psicología estructural). Fueron momentos propios, que junto a la oralidad de los miembros permitieron interpretar las cargas emocionales y sociales que forman parte de la cultura y que se deslizan como líquido, en todos los rincones. Estos acontecimientos, favorables o no, traen consigo sentimientos que permanecen en la memoria colectiva, la cual se traslapa a lo social y quedan en la llamada memoria social y cultural. 
Así mismo, otro de los elementos considerados fue la carga mística conformada de creencias, mitos y rituales transmitidos por generaciones y que de igual manera son parte del sentido identitario de la comunidad, presente desde el origen de la comunidad como el mito fundacional del mormonismo que tal como otras religiones, al creer en la existencia de un ser supremo y en este caso en un personaje capaz de entablar conversaciones con este $\mathrm{u}$ otros seres que marcan las pautas morales de convivencia.

Haciendo un paréntesis y sin el afán de obviar, se esclarece el concepto de cultura, el cual considero fundamental para concebir e interpretar la identidad de una comunidad. Así mismo la historia se encuentra claramente entrelazada con los procesos culturales y estos determinan el sentido de identidad de la agrupación, uniendo entonces, aquellos rasgos o características particulares que permiten al propio o al externo diferenciarse entre las agrupaciones.

El concepto de cultura al igual que la historiografía han sufrido modificaciones. Para Burke el término cultura al inicio se utilizaba estrictamente en las artes o ciencias, posteriormente dirigido a lo popular en la música, medicina u otras; ya en la última generación de la historia cultural "la palabra ha pasado a referirse a un vasto repertorio de objetos (imágenes, herramientas, cosas, etc.) y prácticas (conversación, lectura, juego)" (2004, p. 45).

Fue entonces que para la interpretación de estos procesos culturales se

154 siguió la línea propuesta por Geertz, quien, desde mediados de los noventas, en uno de sus libros recuperó algunos ensayos de su autoría, en los que colocó especial interés en el conocimiento local como un pensamiento social que nace del sentido común conformado por un cúmulo de signos y su simbolismo. Por lo que dicha comunidad fue pensada a través de sus manifestaciones culturales, precisamente con 
estos marcos de referencia y su historicidad. Burke citando a Geertz indicó que la cultura es "un patrón históricamente transmitido de significados encarnados en símbolos, un sistema de concepciones heredadas, expresadas en formas simbólicas mediante las cuales los hombres se comunican, perpetúan y desarrollan su conocimiento de la vida y sus actitudes hacia ella" (2004, p. 54).

Metodológicamente, los estudios culturales sin etnografía suelen ser impensables. Se reconoce que esta modalidad se deprende de la antropología, y en este caso fue la manera de abordar las formas de vida de una comunidad hermética y reservada, quienes para mantenerse y permanecer elaboran códigos que limitan ante los externos, seleccionando cautelosamente a quienes permiten acceso. Dicha labor compete también al historiador, quien interesado en la cultura y en palabras de Burke:

Se ha obrado una transformación gradual en el uso del término $<$ cultura $>$ por parte de los historiadores en los últimos treinta años aproximadamente. Empleando antaño para referirse a la alta cultura, ahora el término incluye asimismo la cultura de la vida cotidiana, es decir, las costumbres, los valores y los modos de vida. En otras palabras, los historiadores se han arrimado a la concepción mantenida por los antropólogos (2004, p. 50).

Si bien el interés en aspectos culturales junto a la complejidad en las ciencias sociales hace necesario considerar la mayor parte de elementos que construyen el todo y que guardan relación entre sí, en este caso se delimitaron aquellos elementos culturales que son parte de la configuración del sentido de identidad de la comunidad. Fue así como se dirigió la mirada hacia la religión, la educación y la familia como las tres grandes dimensiones sociales, considerando las particularidades que conforman a cada una de ellas. 
En este mismo orden se reconocen algunas características propias de la comunidad. En primer lugar, se tomó en cuenta la religión, reflexionando en la apropiación y resignificación de una serie de elementos canónicos que dan sentido a su vida. Así mismo el fundamentalismo, dentro de este ámbito, se considera como causa primigenia para conformarse como comunidad y actualmente es un elemento que funciona como aglutinante para mantenerse $y$ permanecer.

El segundo parámetro o dimensión fue el ámbito educativo, colocando mayor énfasis en la educación informal sea o no intencionada, proveniente de diversas instituciones, con el distintivo de la situación contextual particular de la comunidad mormona.

La tercera dimensión acerca de la composición familiar se determinó en función de la construcción identitaria de esta agrupación mediante sus procesos educativos, más allá de que sean polígama o no, ya que esta estructura está estrechamente ligada con las creencias religiosas incluidas en la primera dimensión. Al interior de la familia se observaron las prácticas cotidianas y se estimó el papel fundamental de la enseñanza en este entorno, interpretando qué sentido de comunidad imaginada construyen en ese espacio.

Hasta este momento se ha mencionado en reiteradas ocasiones la palabra identidad, pero incurrir en este término requiere una conceptualización, para este caso se toma lo expresado por Valenzuela

156 (20I8) quien mencionó que la identidad se conforma de una serie de umbrales, fronteras o marcos intersubjetivos de reconocimiento o clasificación social. Esta puede estar presente en dos sentidos, una es la identidad de pertenencia que se desarrolla en las relaciones cotidianas y la segunda identidad es la de adscripción, considerada como genérica, con la cual no se requiere convivir constantemente con los miembros 
de una comunidad en particular, como su nombre lo dice es la adscripción a cierto grupo o colectividad.

Años antes, este mismo autor desarrollo preceptos que fueron considerados al caracterizar los procesos identitarios de la comunidad en cuestión. Especialmente se incide sobre el sentido de pertenencia como determinante, establecido dentro de lo cotidiano, en donde convergen las dinámicas sociales y se muestra el contenido simbólico ya establecido, en palabras de Valenzuela:

Es en la interacción social donde se articulan los diferentes pactos simbólicos mediante los cuales se constituyen los sujetos y se adscriben en una o varias comunidades imaginarias... de esta manera, la cotidianidad será el ambiente preferente donde se consolidan los pactos simbólicos 'juramentados' pero estos se validan y se insertan en formas institucionalizadas que reproducen los universos simbólicos dominantes (1998, pp. 7273).

Ambas tipologías de identidad se encuentran presentes, sin embargo y debido al número de personas que conforman a la comunidad mormona, así como sus estrechas relaciones familiares y comunales se consideró prioritariamente el alusivo a la pertenencia; en una comunidad en la cual se identifican y conocen casi en su totalidad, debido a sus mismas condiciones. Así mismo esta agrupación tiene una serie de referentes de adscripción ya que al igual que ellos, existen otras comunidades que comparten el mismo mito fundante, la historia de la diáspora, la separación de la iglesia madre y un simbolismo que al mismo tiempo que los identifica como semejantes, los diferencia de los que están afuera y que configuran estas formas de pertenencia. 
Esta misma distinción de pertenencia y adscripción la traslapa a dos tiempos, cotidiano y genérico, correspondientes con lo recién expuesto. Hacer referencia al tiempo implica repensar lo social desde la historicidad, la cual funciona como uno de sus ejes rectores y es un elemento de impacto en el desarrollo y acomodo de la construcción de la identidad, como resultado de una serie de acontecimientos situados en un tiempo y lugar particular.

Los miembros o descendientes de la comunidad mormona fundamentalista son seres sociales, históricos y culturales, al igual que cualquier otro ser humano; por lo que recuperar y considerar los referentes comunes de la agrupación tales como su historia, su situación actual en diferentes ámbitos, aquellos momentos críticos que redireccionaron su camino, sus tradiciones, lo concerniente a la fundación mítica y el simbolismo, fue relevante para comprender el sentido cultural y comunitario de esta agrupación.

El tiempo sirvió como referencia al momento de contextualizar los acontecimientos en el devenir de este conglomerado social y aunque el pasado es difícil de percibir, lo que se hizo fue reconstruir dichos acontecimientos. Definitivamente, el pasado no existe como entidad física, lo que existen son pistas y vestigios, mediante los cuales se realizan las interpretaciones desde el presente. Así que cuando se habla del tiempo histórico se refiere a la interpretación de los sucesos que están presentes en la subjetividad de quien recrea y supone el pasado junto a los comportamientos correspondientes.

Ahora bien, los antecedentes de la historia cultural como una historia interesada en las mentalidades, como ya se puntualizó, inició con un diálogo abierto con otras teorías y métodos considerados pertenecientes a diferentes perspectivas trasdisciplinarias como la sociología o la antropología. Lo que dio las pautas necesarias para 
migrar desde una narrativa de los hechos hacia un genuino interés en analizar las creencias, mitos, ritos y valores como elementos presentes en la cotidianidad. Entonces, sería un error considerar que la historia es una sola condición, se trata más bien de hechos o fuerzas dinámicas que se dirigen hacia un fin determinado, que son recreadas, narradas e interpretadas.

Al hacer hincapié en toda esta carga histórico-cultural se vislumbra la relación de la historia con la designación de los puntos distintivos o los dispositivos para cercar las pautas o condiciones de pertenencia y de adscripción. Por lo que la historia al ser social y cultural envuelve tanto al autoreconocimiento como al heteroreconocimiento, es decir, el cómo se van definiendo como grupo a sí mismos y cómo los representan quienes los ven desde fuera, claro está, siendo una relación en ambos sentidos.

Estas relaciones auto y hetero no se dan solo en el plano del reconocimiento, también en el campo de la representación y de la adscripción. Ambas, al ser relaciones entre lo individual y lo colectivo, muestran una clara articulación entre lo psicológico y lo social; lo que ratifica la integración de una conciencia e identidad en ambas esferas.

Lo anterior dio la pauta para considerar el fenómeno cultural migratorio y fronterizo. Las narrativas recrearon tanto identidades norteamericanas como mexicanas. Si bien algunas tuvieron más fuerza o solidez, se concluyó que ambas, junto a sus propios marcos de convivencia promueven la construcción de un sentido de identidad particular, que independientemente de la credencialización que les nombra de una, otra o ambas nacionalidades, logra conformar un hibridismo entre la persona rural mexicana dedicada a la agricultura o ganadería, principalmente, pero con una carga cultural proveniente del 
país vecino, visible desde el arraigo del idioma hasta las dinámicas dentro del hogar.

Esta mezcla compartida es expresión identitaria de una comunidad que conmemora festividades icónicas de los Estados Unidos de Norteamérica, son bilingües y durante su cotidianidad evocan nostalgias, emociones y representaciones de lo que es migrar o regresar a su país de origen propio o ascendente.

Esta dinámica fue sencilla de determinar al conocer las formas de vida y trabajo que comparten entre dos países, ya que existen una gran cantidad de personas en la colonia que migran y retornan constantemente a su lugar de origen. Pero en adhesión con lo expuesto por García Canclini (20I4) se indica que los procesos migratorios existen en más niveles; las fronteras no solo separan a las naciones, sino que dentro de un mismo territorio nacional existen, como entre países, arquetipos como la segregación, el intercambio y la solidaridad. Esto fue identificable en una historia reciente en la que esta agrupación ha experimentado actos de violencia física y simbólica por parte aquellos que radican geográficamente en espacios cercanos. Para clarificar el punto de unión de lo expresado, este mismo autor indicó que:

En estos procesos -migraciones transnacionales y fracturas internacionales- se combinan identidades múltiples. Lo propio y lo ajeno se entremezclan: pertenecemos a redes que cruzan las fronteras nacionales y a veces nos sentimos extraños en la propia sociedad. Podemos sentirnos extranjeros, no solamente debido a los cambios territoriales sino al tener experiencias de alteridad que suceden en el lugar donde vivimos (p. 46).

Hasta este momento se han detallado puntos clave que fueron producto del trabajo etnográfico, principalmente con entrevistas, observaciones 
y trabajo con documentos. Se trata de un resultado de visitas en diferentes momentos a lo largo de varios años que marcaron la relevancia al categorizar las interacciones intragrupales e intergrupales.

Para profundizar en esto, se retomaron las particularidades de las interacciones sociales y continuando en una misma dirección, adueñándose de los conceptos básicos de Berger y Luckmann quienes a mediados de los años sesentas, partieron de reconocer a la vida cotidiana como un mundo ordenado en el cual se construye la naturaleza del pensamiento social con una serie de significados compartidos y esta subjetividad surge a partir de las interacciones sociales.

Es indispensable aclarar, al lado de Berger y Luckmann, que los fenómenos sociales se conciben en tres momentos, aunque desposeedores de secuencia, le caracterizan a la sociedad en un proceso dialéctico: externalización, objetivación e internalización. Este último punto de internalización surge cuando el individuo otorga el significado de un acontecimiento objetivo y es la base para "la aprehensión del mundo en cuanto realidad significativa y social" (Berger y Luckmann, 2003, p. 165). Las personas asumen que el significado no es único, sino que existen otros quienes le brindaron un significado previo.

Así mismo, estos teóricos elaboraron una categorización en cuanto a los procesos de socialización primaria y secundaria presentes durante la internalización de la realidad. En cuanto a los procesos primarios son aquellos establecidos durante el intercambio cotidiano, presentes en la convivencia familiar. Se trata de la primera socialización de los individuos y a través de la cual se convierten en miembros sociales, lo que desata un proceso con una fuerte carga emocional. 
En el caso particular investigado se estableció a la familia en función del significado que le otorga la misma comunidad y no como la clásica visión occidental de la familia nuclear. En esta agrupación coexisten, imaginan y conviven en lo cotidiano con lo que para ellos es su gran familia, una representación de la unión de varias mujeres con el mismo hombre, por lo cual varios hijos comparten el mismo padre. De igual manera, estas relaciones de coexistencia entre aquellas familias de diferente configuración con las del matrimonio plural están presentes, debido a su reciente origen como colonia, ya que comparten en sus antecedentes esta característica del matrimonio plural.

En cuanto a la socialización secundaria, se trata de los procesos posteriores a la primaria y ocurre mediante la interacción de este miembro de la sociedad en diversos espacios. En este caso se consideraron a la comunidad y las escuelas a las que acuden los niños y jóvenes como los dos espacios principales en esta socialización. Ambos, al igual que la familia se suponen como agentes socializantes y educativos, pero se encuentran en este nivel. Las escuelas ya sean oficiales o las instituidas dentro y por la comunidad, se explicaron desde los contenidos que manejan hasta los ejes mismos de la enseñanza. Precisamente dentro de estos procesos se hizo énfasis en identificar a la educación informal como una manera de configuración de la identidad, claramente fusionada a lo social y que ayuda a entender el sentido que se ha mencionado.

Hasta aquí se han determinado algunas formas de relación encontradas en las interacciones cotidianas, que en una lógica comunitaria apuntan hacia relaciones socio-afectivas, desde lo humano cambiantes, dependiendo del momento y las personas. Precisamente así fue como se alumbró el campo de la subjetividad en aquello que, a pesar de no ser visible ante la mirada, estuvo ansioso de liberarse mediante la 
interpretación, delimitada en este caso por los elementos antes mencionados.

En este sentido, la complejidad fue constitutiva de la interpretación de esta organización social, personas con prácticas comunes y espacios en donde fue posible identificar las manifestaciones que forman parte de su mundo y que son al mismo tiempo expresiones culturales.

El interés en procesos subjetivos encareció partir de un concepto de cultura simbólica dentro de un campo social, para otorgar significados con fines de organización y praxis, en donde el sentido común juega un papel fundamental al ajustar las formas y medios que moldean las prácticas sociales. El término simbólico se entiende desde las reflexiones de Giménez (2005) quien retoma a Clifford Geetz y John Thompson para definirlo como:

El mundo de las representaciones sociales materializadas en formas sensibles, también llamadas 'formas simbólicas', y que pueden ser expresiones, artefactos, acciones, acontecimientos y alguna cualidad o relación... lo simbólico recubre el vasto conjunto de los procesos sociales de significación y comunicación (p. 68).

Se recurrió a este término, debido a que en este gran universo coexiste el simbolismo, que refiere a la significación que las personas otorgan a lo percibido, esta interacción con lo externo se da en el plano de la imaginación al conferir el significado y el sentido. Por lo que surge la necesidad de definir lo que es el símbolo, que de acuerdo con lo expresado por A. Lalande se refiere a "todo signo concreto que evoca, por medio de una relación natural, algo ausente o imposible de percibir" (Durand, I968, p. I3). Y precisamente este "signo remite a un significado inefable e invisible, y por eso debe encarnar concretamente 
esta adecuación que se le evade, y hacerlo mediante el juego de las redundancias míticas, rituales, iconográficas, que corrigen y completan inagotablemente la inadecuación" (p. 2I).

Las interacciones pueden o no poseer significados, la diferenciación estriba en incluir los elementos imaginativos y atribuirle significado a los acontecimientos $\mathrm{u}$ objetos con los que se tiene contacto, necesariamente bajo los marcos socioculturales correspondientes. Este universo simbólico y la vida cotidiana fueron inseparables, ambos comprometidos con los símbolos y las representaciones de la realidad, permiten convivir y elaborar un pensamiento significativo comprensible por aquellos, siempre y cuando compartan determinado marco social e interpretativo.

En este aspecto y siguiendo a Castoriadis, Valenzuela mencionó que "el concepto de imaginario alude principalmente a formas culturales que funcionan como formas instituidas e instituyentes. No es solo la conformación de ciertos sentidos o de imágenes, sino que son sentidos incorporados en prácticas institucionalizadas como la educación" (J.M. Valenzuela, comunicación personal, o5 de julio de 2018). Entonces el entendimiento del imaginario integra el sentido humano y su paso de lo corporal a lo etéreo, siendo en este conducto que las representaciones muestran la relación entre lo imaginado y las interacciones con su contexto social.

En cuanto a la relación del imaginario y su papel dentro de historia, se 164 cita a Escobar quien indicó que "la palabra 'imaginario' se volvió una noción y un concepto en el que la solidaridad del presente y del pasado es la más pertinente justificación de la historia" (Escobar, 2000, p. II). Visto desde siglos anteriores con la escuela francesa, el imaginario ha de pertenecer a la historia, posibilitando la escritura de una historia que pareciera ser sencilla por recuperar lo local, pero interesada en el 
mundo de las ideas. Como fue el caso de la comunidad centro de la investigación.

Para ultimar con este aspecto, en el siguiente párrafo se contempla la articulación de dichos términos con los aspectos identitarios. Se cita nuevamente a José Manuel Valenzuela, quien apoyó en la redirección de las categorías, ejes y dimensiones del trabajo investigativo, al mencionar que:

Las identidades imaginarias son pactos simbólicos que influyen en la práctica social y constituyen recursos para la articulación de proyectos. Son los fantasmas del imaginario que cobran forma y vida en la conciencia social; arquetipos que dibujan a los hombres y mujeres reales. El individuo no se reconoce en sí mismo sino en los fantasmas colectivos, y cuando más se asemeja a la entelequia, nuevos fantasmas se transparentan o cobran fuerza. De la manga mágica de las identidades colectivas han nacido grupos, etnias, nacionalidades, Estados-nación, movimientos sociales, culturas alternativas, etcétera (2000, p. I6).

\section{Consideraciones finales}

Unido al interés principal de este texto en función de mostrar las relaciones de la historia cultural con las caracterizaciones propias de la colonia de mormones fundamentalistas, se reconoce que fue un reto la interpretación de lo intangible. Con ello se hizo necesario mostrar el posicionamiento investigativo, el cual fue colocar al centro al ser humano como un ser social y emocional, que desde la historiografía se reconoce como poseedor de un bagaje histórico y cultural, pero creador de su propia realidad. Así que, sin ser impositivo, se logró analizar e 
interpretar su pensamiento para escribir y dar a conocer esta historia que incluye lo social, cultural, simbólico e imaginativo.

No fue la intención cuestionar o juzgar la identidad, lo que se buscó fue deconstruir aquellos procesos subjetivos y simbólicos que conforman el pensamiento social en su sentido de identidad. De igual forma, se concibió a la identidad como interminable, similar a un espiral, en donde la base identitaria genera nuevos imaginarios que se adhieren a los ya instituidos pero con la fuerza necesaria para ser instituyentes.

Es importante resaltar que la distinción de los elementos constitutivos de la producción y reproducción de las pautas culturales y del imaginario, fueron seleccionados porque funcionan como argamasa, ya que es así como se construyen las relaciones con otredades y alteridades para posicionarse y asumir su identidad.

Se concluye que todo el trabajo narrado hasta aquí, fue posible conocerlo y recuperarlo con apoyo de las herramientas provenientes de la historia cultural, la cual brinda los elementos teóricos y metodológicos suficientes para acercarse a la interpretación de los aspectos simbólicos.

\section{Referencias}

Berger, P., y Luckmann, T. (2003). La construcción social de la realidad. 166 Buenos Aires, Argentina: Amorrortu editores.

Burke, P. (2004). ¿Qué es la historia cultural? Barcelona, España: Paidós.

Durand, G. (1968). La imaginación simbólica. Buenos Aires, Argentina: Amorrortu. 
Escobar, J. C. (2000). Lo imaginario entre las ciencias sociales y la historia. Medellín, Colombia: Fondo Editorial Universidad EAFIT.

García, N. (20I4). "El mundo entero como un lugar extraño.” En J. M. Arce, Trasnfronteras: fronteras del mundo y procesos culturales. México, D.F, México: El Colegio de la Frontera Norte.

Geertz, C. (1994). Conocimiento local. Ensayos sobre la interpretación de las culturas. Barcelona, España: Paidós.

Giménez, G. (2005). Teoría y análisis de la cultura (vol. I). México: CONACULTA.

Santana, J. M. (2005). Paradigmas historiográficos contemporáneos. Barquisimeto, Venezuela: Fundación Buria.

Valenzuela, J. M (1998). “Género y familia”. En J. Valenzuela, \& V. Salles, Vida familiar y cultura contemporánea. México, D.F, México: CONACULTA.

Valenzuela, J. M. (julio de 20I8). (S. Liddiard, Entrevistador). Internacional, y puede ser usados gratuitamente para fines no comerciales, dando los créditos a los autores y a la revista.

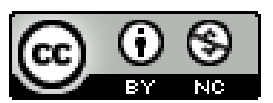


168 